\title{
Habitat Stress and Arterial Disease in Elephants
}

\author{
By Sylvia K. Sikes
}

Elephant management in East African reserves and national parks has become one of the urgent conservation problems of today. In this study of the African savanna elephant, Dr Sikes shows that two diseases of the heart and arteries, found only in lowland elephants, were directly associated with the degeneration of the habitat when elephant numbers began to build up in the Tsavo National Park in Kenya and the Queen Elizabeth and Murchison Falls National Parks in Uganda. The two diseases thus appear to be natural factors tending to limit the elephant populations in these reserves, and she suggests four lessons to be drawn from this discovery by those concerned with elephant management in national parks.

WHAT constitutes 'stress' to an African elephant? Is stress related to arterial disease in elephants? During my recent survey of cardiovascular disease in free-living wild mammals and birds in East Africa over the period $1964-65^{*}$, data were collected from 68 different species. Of these, $13 \mathrm{had}$ arterial disease in which abnormal fatty deposits were found in the artery walls, resembling the disease of atheroma (fatty arteries) in man. Only in the African elephant and the chimpanzee, however, were these deposits found to interfere in any way with the circulation of the blood and thus to endanger the health and survival potential of the animal. A few, of which the most important was the elephant, also had another arterial disease, medial sclerosis, in which calcium salts were deposited in the artery walls. In captive and experimental animals of many different species, occlusive arterial disease is comparatively common. (Fiennes 1965; Finlayson 1965; Lindsay and Chaikoff 1963).

The elephant was selected from among the susceptible wild species for intensive study for several reasons. Unlike the chimpanzee, it is in no special need of protection: on the contrary, in some areas it requires urgent culling. It is large enough, and both individuals and herds are distinctive enough, to be recognisable over prolonged observational periods. A great deal of information is available about its habits, past characteristics and anatomy (Sanderson 1963). A considerable body of scientific information is currently being built up on the characteristics of non-migratory African elephant populations in the present-day partial restriction of national parks and reserves (Buss 1961, Bere 1966, Buss and Savidge 1966, Johnson and Buss 1965, Short 1966). And finally, its life-span is broadly comparable to that of man (Sikes 1966b), and it is therefore reasonable to suppose that the pathogenesis of spontaneous arterial disease may proceed over a comparable period of development.

*Financed by the British Heart Foundation, whose grant is gratefully acknowledged. 


\section{STUDIES IN DIFFERENT HABITATS}

\section{The 'control' or natural habitat}

To avoid the misleading effect of confining the studies to the somewhat abnormal or semi-artificial environment (McDiarmid 1962) of national parks and their environs, it was decided to study a comparable number of elephants from unspoiled, unrestricted, indigenous forest areas to serve as the 'control' group. There is a great deal of historical evidence that the 'natural' and preferred environment of the African elephant (of both the savanna and 'forest' races) is indigenous gallery forest. There is also abundant evidence that, in the past, elephant used these forests as refuges for mating and calving during the dry seasons, and only crossed the savanna woodland during their long-distance migrations, (Bere 1966), or utilised it transitorily in temporary, rainy-season meanderings. Moreover, as has been noted by Frechkop (1955), the structure of the eye of the elephant is typically that of a forest dweller, adapted primarily to light of low intensity. For the purpose of this project, the montane indigenous forests and adjacent alpine moorlands of Kenya and Uganda were therefore chosen for the 'control' study.

In these areas, there is still adequate scope for unrestricted migratory movement and for the elephant to be fully mobile and active. Their population growth is kept in check by the combined activity of licensed ivory hunters and game control officers, just as in the past it was kept in check by tribal hunters for meat and ivory. The diet is varied and abundant, and the terrain physically demanding and interesting. They have privacy and protection from the tropical heat and sunlight when mating and calving. It is unfortunate that comment has crept into some recent scientific literature, suggesting that past writers were incorrect in their observations that elephant were naturally adapted to a forest-based way of life, that their preference was to mate and calve in private, and their preferred fodder arboreal (Bere 1966; Short 1966).

Indeed, many of the earlier writers (Bell 1960; Rushby 1965; Selous 1881; Watteville 1935) were most careful observers of elephant behaviour and had the privilege, denied to all but a few nowadays, of seeing elephants living their lives in the manner to which they are basically adapted. Today few elephant populations, either in Africa or Asia, still have access to the full range or kind of territory which they would use naturally if it were available to them.

There is no doubt that individual elephants and elephant herds may prove to be temporarily very adaptable, and, even in the captivity of zoos, as well as in the frustrating limitations of the modern overcrowded national parks, may learn from sheer necessity to adopt new behaviour patterns and accept an abnormally restricted diet. As will be seen, the decision to make a study of elephant in extensive montane habitats has proved to be fully justified.

\section{Degenerate or 'stressed' habitats}

In contrast to the montane forest habitats, two other contrasted 'degenerate' or 'stressed' habitat types were chosen. One was the degenerate savanna woodland, now consisting mainly of grassland, in the Queen 
Elizabeth National Park and Murchison Falls National Park in Uganda, and their environs. The other was the Tsavo National Park and its environs, in Kenya. Both these habitat types exhibit features characteristic of advancing ecological imbalance, but differ in the type of vegetational cover as well as in their hydrology. The former - subsequently referred to here as 'grassland' - has constant, abundant surface water supplies and has been fully described by Buechner \& Dawkins (1961), Buechner et al (1963) and others (Anon. 1962). The latter, referred to here as 'scrubland', is a naturally arid area, carrying sparse thorn scrub and acacia trees, with isolated, remote and unreliable surface water supplies, which tend to become reduced or even to dry up completely in the dry seasons. The surface soils form a thin, infertile layer, readily eroded and never able to carry a profuse vegetational cover (Sikes 1966c).

\section{DISEASES FOUND IN LOWLAND ELEPHANTS}

In this study project, elephants of both sexes, representing all main age groups, were collected from each of the three habitat types and examined post mortem in the field. Comprehensive data on growth, samples of normal tissues, and material from diseased organs, were collected and taken back for detailed analysis at the Nuffield Institute of Comparative Medicine, Zoological Society of London. When the cardiovascular material was analysed quantitatively, the results were startling, and, although this was not the primary aim of the research project, the studies were soon seen to be directly relevant to the question of elephant management in the East African national parks.

Two different types of 'spontaneous' arterial disease were found, each having a separate and distinct pattern of development within the walls of the arteries and probably each having a separate cause, or complex of causes. These diseases were entirely confined to elephants from the lowland habitats.

The first of these was medial sclerosis. In this disease, the muscular (posterior) part of the main artery of the body (the aorta), the coronary arteries (supplying oxygenated blood to the heart muscle) and the main arteries of the neck, and limbs, progressively accumulate deposits of calcium salts until they eventually resemble narrow, rigid pipes. In an advanced state, this disease may impair the blood supply to the muscle of the heart itself, predisposing the animal to heart failure; to the head, predisposing it to 'stroke'; to the limbs, causing lameness and stiffness; and to the back and flanks, giving a 'wasted' appearance and dry calloused skin. Elephants with this condition frequently stand with the head drooping forward from the shoulders, and they tend to scratch and rub the skin with unusual frequency. The ears may drop permanently into the lopeared position, when they can no longer maintain their 'punkah' movement so essential for heat regulation in the elephant. In cases where the onset of this disease has occurred during calfhood or adolescence the physical growth of the animal is impaired, and in advanced stages the elephant may exhibit premature signs of old age and senility.

No case of this disease was found in elephants of any age group collected in the montane habitats. In the scrubland, it occurred in elephants of the 
younger age groups, namely in calves, juveniles, and a few sub-adults (i.e. sexually mature but not yet fully grown animals) of both sexes. In the grassland habitat, this condition was seen in some degree in every specimen examined, including some adult elephants which - according to their molar age - should have been in their prime, but which were already decrepit and somewhat immobile. The latter elephants, when examined post mortem, were found already to have their circulatory efficiency limited by this rigidity of all the larger arteries, including parts of the coronary arteries supplying the heart muscle.

The second disease was very similar to human atheroma. In this disease, excessive deposits of fat are laid down in the inner lining of the arteries, the pattern of development being distinct from that of medial sclerosis (which occurs in the middle layer of the artery wall) and apparently being directly related to the flow pattern of the blood itself within the vessel. In a few advanced cases of this disease seen in elephants, the blood circulation may have been slightly impaired. In the elephants studied, this disease appeared to be more in the nature of an excessive fatty deposition, with the main foci at points in the lining of the arterial wall which normally contain very small quantities of fatty deposits. The possible cause or causes of this condition could not be identified, and indeed in man the cause of atheroma is still uncertain. It was clear, however, that while the excessive deposition of fat in the arterial lining did not occur at all in montane elephants, it was maximal in scrubland ones, and also occurred slightly in grassland elephants. In a few animals, both diseases were found to be co-existent.

Another feature of great interest was the difference in the shape and character of the heart in the montane, as compared with the lowland elephants. In the former, the heart was firm, and longer than in the lowland elephants, somewhat similar in appearance to that of a horse. In contrast, the lowland elephants had rather 'square' shaped, flaccid hearts, showing clearly the divided apex previously thought to characterise all elephants. Some of the lowland elephants with medial sclerosis of the arteries also had abnormalities of certain of the internal valves of the heart.

\section{Disease and habitat degeneration}

The results were tested quantitatively, and it appeared that medial sclerosis in elephant first begins to develop very soon after the onset of habitat degeneration and habitat restriction. It seems most likely that it is the direct result of the destruction of shade cover essential to elephants of all ages, and especially important to calves, juveniles and sub-adults (adolescents) (Sikes, in press). It is of interest that this disease is at present commonest in the under-twenty-fives in the scrubland habitat. This age group contains elephants calved since the early stages in the closure of the coastal forest refuges and migration routes, the subsequent demarcation of the Tsavo National Park, and the installation there of artificial water holes to provide water throughout the dry seasons. Coincident with these events, was the trend for the elephant herds to abandon their migratory habit, take up residence in the park and its immediate neighbourhood, and to overwork the inadequate vegetation of the arid scrubland beyond its 
regenerative capacity. (Sikes, 1966).

In the case of the Uganda grasslands, the degeneration of savanna woodland to grassland is far more advanced than that of the Tsavo scrubland, and here the disease affected $100 \%$ of the elephants examined in all age groups.

Since the second disease, elephant atheroma, was maximal in the Tsavo scrubland and not generally advanced in the Uganda grassland, it would seem to be due to causes other, or additional to, sun-stress. We may speculate as to whether some item of the diet may be the cause of some metabolic imbalance in the normal physiological processes of the elephant: this could result either in the failure of some mechanism controlling the deposition of arterial fat, or perhaps in an excessive tendency to store fat in the arterial lining. Perhaps we might expect some hormonal imbalance to develop, associated with the early stages in the frustration of the migratory habit; the enforced changes in the mating and calving habits necessitating the fulfilment of these events exposed to sun, wind, rain and predators, and perhaps even the disruption of the breeding cycle from that formerly related to seasonal migrations and herd re-grouping, to one now occuring non-seasonally throughout the year.

\section{Stress and cardiovascular disease}

Whatever the exact causes of these disease patterns, their occurrence is found to be directly associated with the onset and progress of habitat degeneration, consequent upon the demarcation of protected areas and the build-up within these of elephant populations exceeding their carrying capacity.

The stresses which appear to be directly connected with the occurrence of these diseases are:

(i) prolonged exposure to unmitigated sunlight;

(ii) overpopulation;

(iii) a restricted diet;

(iv) frustration of the migratory habit, associated with a breakdown of environmental conditions suited to the birth and nurture of young calves, and with boredom and lack of exercise for the adults.

The effects of irregular non-excessive hunting, of altitude, and of cold and humidity in unspoiled, indigenous, montane forests do not appear to be in any way stressful to elephant and, if anything, seem to act as beneficial stimuli. Presumably, if deforestation and encroachment by human settlements became extensive on the montane ranges, a similar degeneration and stress pattern might build up in these areas also. Indeed, there is evidence on Kinangop mountain and the Ruwenzori range that such degeneration has already begun to take place.

\section{THE PRACTICAL APPLICATION}

Is there a practical application of the results of this survey to elephant management in national parks?

If there are any lessons to be learned about elephant management in the 
parks and reserves, the findings of this survey seem to suggest: firstly, that planned elephant control should begin as early as possible after the demarcation of any park or protected area, and the situation be constantly monitored thereafter. Secondly, it appears that the needs of the species should be interpreted not only according to studies made upon degenerate elephant populations in already stressed habitats, but by comparison with healthy elephants living in natural unstressed 'control' habitats, in order to try to discover the true norm. Thirdly, there is a strong indication here that selective culling and cropping would be more meaningful than random elimination techniques, if good breeding stock is to be husbanded within the restricted areas of national parks (Sikes 1966a).

'Spontaneous' arterial diseases described above, resulting from habitat degeneration, overpopulation and stress, appear to be natural factors tending to limit populations and reduce longevity. It is apparent that they tend to strike mainly at points of weakness in the population. Perhaps we should be wise to emulate the selective techniques of nature when deciding how to 'manage' wild animal populations in parks and reserves.

\section{Acknowledgments}

The co-operation of the Directors and staff members of the Game and National Park Departments throughout this survey is gratefully acknowledged, as is the assistance of all who contributed to its success. The help and loyalty of the African assistants of the mobile research unit is particularly acknowledged.

\section{REFERENCES}

ANONYMOUS, 1962. Uganda National Parks Handbook. Publ. Trustees of the Uganda National Parks, Kampala.

BELL, W. D. M., 1960. Bell of Africa. London: Spearman.

BERE, R. M., 1966. The African Elephant. London: Barker.

BUECHNER, H. K., BUSS, I. O., LONGHURST, W. M. \& BROOKS, A. C., 1963. Numbers and migration of elephants in Murchison Falls National Park, Uganda. J. Wildl. Mgmt. 27 : 36-53.

BUECHNER, H. K. \& DAWKINS, H. C., 1961. Vegetation change induced by elephants and fire in Murchison Falls National Park, Uganda. Ecology 42: 752-766.

BUSS, I. O., 1961. Some observations on food habits and behaviour of the African elephant. J. Wildl. Mgmt. 25: 131-148.

BUSS, I. O. \& SAVIDGE, J. M., 1966. Change in population number and reproduction rate of elephants in Uganda. J. Wildl. Mgmt: 30: 791-809.

FIENNES, R. N. T-W- 1965. Atherosclerosis in wild animals in 'Comparative Atherosclerosis' (Eds: J. C. Roberts \& R. Straus). New York: Harper.

FINLAYSON, R., 1965. Spontaneous arterial disease in exotic animals. J. Zool. 147: 239-343.

FRECHKOP, S., 1955. Super-ordre des ongulés: in Traité de Zoologie (Ed: P. P. Grassé) 17: p. 496.

LINDSAY, S. \& CHAIKOFF, I. L., 1963. Naturally occurring arteriosclerosis in animals: a comparison with experimentally induced lesions: in Atherosclerosis and its Origin. (Eds: M. Sandler \& G. H. Bourne) London: Academic Press.

MCDIARMID, A., 1962. Diseases of free-living wild animals. F.A.O. Afr. Studies, No. 57: p. 2.

RUSHBY, G. G., 1965. No more the Tusker. London: Allen. 
SELOUS, F. C., 1881. A Hunter's wanderings in Africa. London.

SHORT, R. V., 1966. Oestrous behaviour, ovulation and the formation of the Corpus luteum in the African elephant. E. Afr. Wildl. J. 4: 56-68.

SIKES, S. K., 1966a. The elephant problem in Africa: random slaughter or selective husbandry? Afr. Wildl. 20: 225-237.

SIKES, S. K., 1966b. The African elephant, Loxodonta africana: a field method for the estimation of age. J. Zool. 150: 279:295.

SIKES, S. K., 1966c. The African elephant, the background to its present-day ecological status in the Murchison Falls (Uganda) and Tsavo (Kenya) National Parks and environs. Rev. Zool. Bot. Afr. 74: 255-272.

SIKES, S. K. (in press) (d) Observations on the ecology of arterial disease in the African elephant (Loxodonta africana) in Kenya and Uganda. (Symposium on Comparative Nutrition in Wild Animals: 10th/11th November 1966, Zool. Soc. London).

WATTEVILLE, Vivienne de (1935. Speak to the Earth. Wanderings and reflections among elephants and mountains. London: Methuen.

\section{Birds of Japan}

\section{The Birds of Nippon, by Dr Nobusake Taka-Tsukasa. Maruzen} Company Ltd, Tokyo, US $\$ 30$.

This heavy tome of 702 folio pages amounts to one of the oddest bird books your reviewer has ever seen. The author, a distinguished Japanese ornithologist, died nine years ago. The book has been put together by various friends, and is sponsored by no less than three forewords from other distinguished ornithologists, including Jean Delacour. A note by the author's widow, dated April 1967, concludes the volume with the following moving words: 'In conclusion I would like to mention that the two colours of the cover of this book are those of the uniform of the Royal Guardman of London of which my deceased husband was very fond and often told us admiringly.'

For better or for worse, inside the scarlet and black covers there is little guardsman-like order. A mass of undigested information has been left more or less as originally compiled by Dr Nobusuke; but in some cases further confused by inexpert editing in English. Despite the title, too, the book only deals with the pheasants and partridges, waders, rails and cranes of Japan. These are followed by a shortish (15 page) supplement on birds recorded from the islands of Bonin and Micronesia, very sketchy; then an elaborate treatment of a section of the parrots, mainly from Australia and South Africa, nothing to do with Japan.

For each Japanese bird, species and sub-species, any scrap of information from any source in Japan is listed serially, even down to single records for common birds. In nearly every case the author is cited, with a reference, though the date (even month) is frequently omitted. For instance, on page 388 we read that the coot Fulica atra breeds commonly on a lake in Honshu according to Dr Kuroda. Two pages later the same authority and the same reference are quoted as saying that he saw six or seven coots on August 15th on the same lake, differently spelt. The bewildering effect of reading literally pages of such undigested reports is accentuated by frequent repetition, sometimes contradiction. as well as abundant misprints.

Another remarkable feature of a remarkable volume is the listing of nonJapanese vernacular names which the author has collected. For the coot these fill a page, including twenty-three examples in German, eight in Russian and twelve in 'Siberian', not to mention four in Finnish and three in 'Lettish'. 


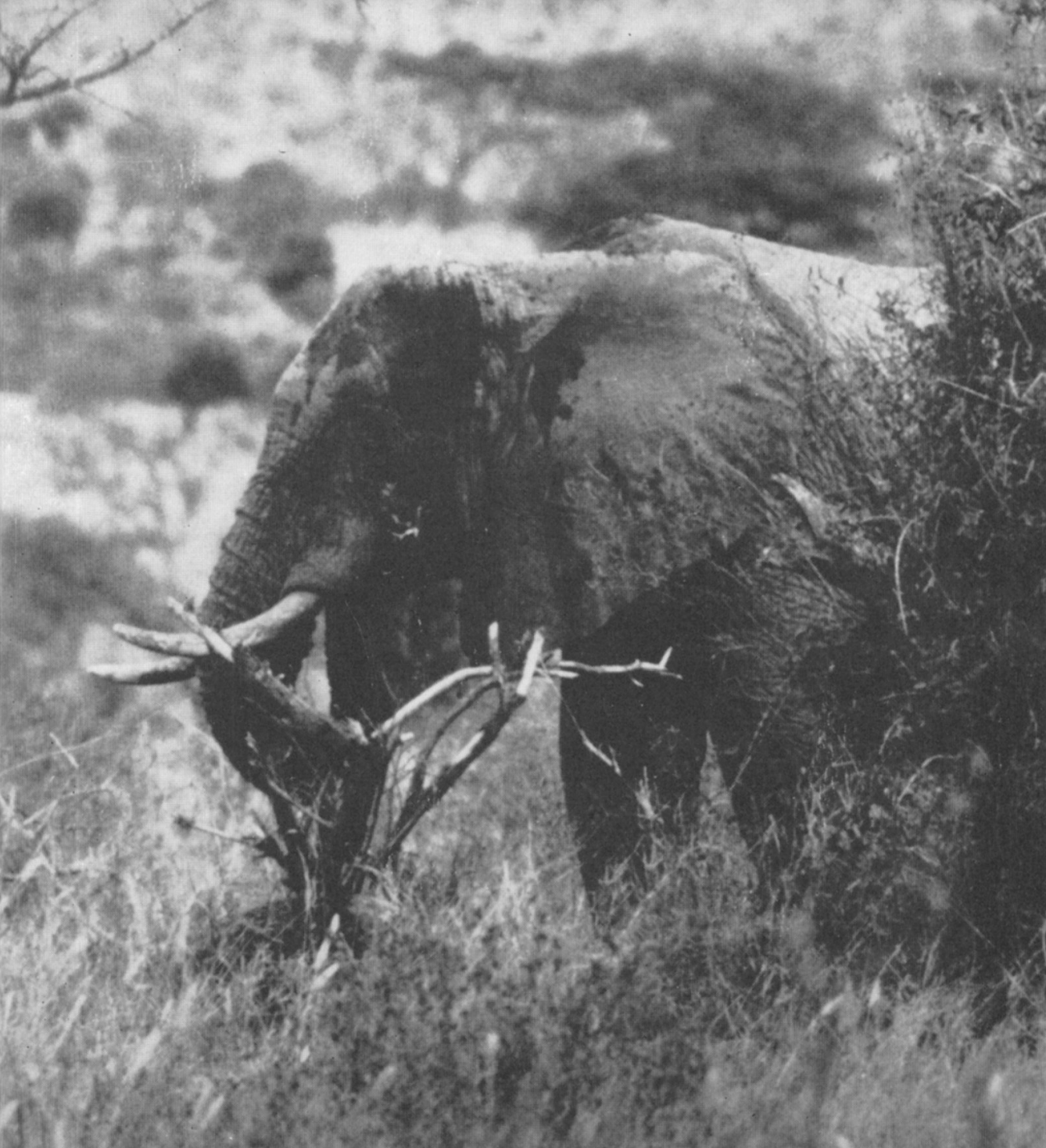

Plate 12: 'SCRUBLAND' ELEPHANT with drooping head, showing signs of chronic ill health. This animal was blind in one eye and also showed some dysfunction of the trunk.

Sylvia K. Sikes. 
